NASA/TM-2004-213080

\title{
Experimental Investigation of a High Pressure Ratio Aspirated Fan Stage
}

\author{
Ali Merchant and Jack L. Kerrebrock \\ Massachusetts Institute of Technology, Cambridge, Massachusetts \\ John J. Adamczyk and Edward Braunscheidel \\ Glenn Research Center, Cleveland, Ohio
}


Since its founding, NASA has been dedicated to the advancement of aeronautics and space science. The NASA Scientific and Technical Information (STI) Program Office plays a key part in helping NASA maintain this important role.

The NASA STI Program Office is operated by Langley Research Center, the Lead Center for NASA's scientific and technical information. The NASA STI Program Office provides access to the NASA STI Database, the largest collection of aeronautical and space science STI in the world. The Program Office is also NASA's institutional mechanism for disseminating the results of its research and development activities. These results are published by NASA in the NASA STI Report Series, which includes the following report types:

- $\quad$ TECHNICAL PUBLICATION. Reports of completed research or a major significant phase of research that present the results of NASA programs and include extensive data or theoretical analysis. Includes compilations of significant scientific and technical data and information deemed to be of continuing reference value. NASA's counterpart of peerreviewed formal professional papers but has less stringent limitations on manuscript length and extent of graphic presentations.

- TECHNICAL MEMORANDUM. Scientific and technical findings that are preliminary or of specialized interest, e.g., quick release reports, working papers, and bibliographies that contain minimal annotation. Does not contain extensive analysis.

- CONTRACTOR REPORT. Scientific and technical findings by NASA-sponsored contractors and grantees.
- CONFERENCE PUBLICATION. Collected papers from scientific and technical conferences, symposia, seminars, or other meetings sponsored or cosponsored by NASA.

- SPECIAL PUBLICATION. Scientific, technical, or historical information from NASA programs, projects, and missions, often concerned with subjects having substantial public interest.

- TECHNICAL TRANSLATION. Englishlanguage translations of foreign scientific and technical material pertinent to NASA's mission.

Specialized services that complement the STI Program Office's diverse offerings include creating custom thesauri, building customized databases, organizing and publishing research results ... even providing videos.

For more information about the NASA STI Program Office, see the following:

- Access the NASA STI Program Home Page at http://www.sti.nasa.gov

- E-mail your question via the Internet to help@sti.nasa.gov

- Fax your question to the NASA Access Help Desk at 301-621-0134

- Telephone the NASA Access Help Desk at 301-621-0390

- Write to:

NASA Access Help Desk

NASA Center for AeroSpace Information 7121 Standard Drive

Hanover, MD 21076 
NASA/TM-2004-213080

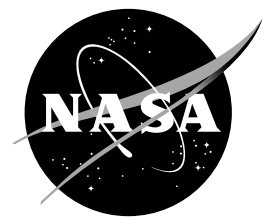

\title{
Experimental Investigation of a High Pressure Ratio Aspirated Fan Stage
}

\author{
Ali Merchant and Jack L. Kerrebrock \\ Massachusetts Institute of Technology, Cambridge, Massachusetts \\ John J. Adamczyk and Edward Braunscheidel \\ Glenn Research Center, Cleveland, Ohio
}

Prepared for the

Turbo Expo 2004

sponsored by the American Society of Mechanical Engineers

Vienna, Austria, June 14-17, 2004

National Aeronautics and

Space Administration

Glenn Research Center 


\section{Acknowledgments}

The authors wish to acknowledge the support provided by DARPA and the AFOSR, which respectively funded and monitored this work. Pratt \& Whitney Aircraft Engines collaborated in the early phases of the design and Honeywell Aircraft Engines carried out the detailed mechanical design and structural analysis of the stage.

TURBOCAM of Dover, New Hampshire, fabricated the stage, and Wilson Composites of Folsom, California, executed the composite winding of the rotor. Individuals who made large contributions include Professors Alan Epstein and Mark Drela of MIT, and Dr. Anthony Strazisar, Dr. Randall Chriss, and Scott Thorp of NASA Glenn Research Center.

Available from

NASA Center for Aerospace Information 7121 Standard Drive

Hanover, MD 21076
National Technical Information Service 5285 Port Royal Road Springfield, VA 22100

Available electronically at http:/ /gltrs.grc.nasa.gov 


\title{
Experimental Investigation of a High Pressure Ratio Aspirated Fan Stage
}

\author{
Ali Merchant and Jack L. Kerrebrock \\ Massachusetts Institute of Technology \\ Cambridge, Massachusetts 02139 \\ John J. Adamczyk and Edward Braunscheidel \\ National Aeronautics and Space Administration \\ Glenn Research Center \\ Cleveland, Ohio 44135
}

\section{ABSTRACT}

The experimental investigation of an aspirated fan stage designed to achieve a pressure ratio of $3.4: 1$ at $1500 \mathrm{feet} / \mathrm{sec}$ is presented in this paper. The low-energy viscous flow is aspirated from diffusion-limiting locations on the blades and flowpath surfaces of the stage, enabling a very high pressure ratio to be achieved in a single stage. The fan stage performance was mapped at various operating speeds from choke to stall in a compressor facility at fully simulated engine conditions. The experimentally determined stage performance, in terms of pressure ratio and corresponding inlet mass flow rate, was found to be in good agreement with the $3 \mathrm{D}$ viscous computational prediction, and in turn close to the design intent. Stage pressure ratios exceeding 3:1 were achieved at design speed, with an aspiration flow fraction of $3.5 \%$ of the stage inlet mass flow. The experimental performance of the stage at various operating conditions, including detailed flowfield measurements, are presented and discussed in the context of the computational analyses. The sensitivity of the stage performance and operability to reduced aspiration flow rates at design and off-design conditions are also discussed.

\section{INTRODUCTION}

The work reported here constitutes one element of a program being conducted by the MIT Gas Turbine Laboratory and its collaborators to develop and validate the technology for design of axial compressors that incorporate control of flow separation by aspiration (or suction) of the viscous flows at diffusion-limiting locations. These include points of impingement of passage shocks, just ahead of diffusion due to flow turning on the blade suction surface, and in corners of the flow path.

The intent of this particular element of the aspirated compressor program was to assess the limit of pressure ratio attainable with aspiration in a single stage, within conventional tip speed limits as set by structural considerations. Preliminary calculations indicated that aspiration should enable an approximate doubling of the work of a stage, while maintaining attached flow [1]. Prior to the work reported here, a moderately aggressive aspirated transonic fan stage, with a pressure ratio of 1.6 and tip speed of $750 \mathrm{feet} / \mathrm{sec}$, was designed and tested at MIT as a first step in demonstrating the utility of aspiration [2]. Consistent with the more aggressive design space of supersonic high through-flow fans, the design objective for the present stage was set as a pressure ratio of approximately 3.4 at a tip speed of 1,500 $\mathrm{ft} / \mathrm{sec}$. A rotor-tip shroud was included in the design to ensure that tip-clearance effects did not limit the stage pressure ratio. Detailed design calculations using a MISES-based approach developed at MIT, followed by 3D viscous analyses carried out at NASA Glenn Research Center, confirmed the viability of the initial choice of pressure ratio [3].

While the principal emphasis of this work was on attaining high work per stage, careful attention was also paid to minimizing the aspiration requirement and achieving acceptable through-flow efficiency, which is the adiabatic efficiency of the compressor based on the stator (or rotor) outflow. This through-flow efficiency includes the effects of shock losses in the core flow and viscous losses that influence the entropy of the outflow of the compressor. It does not embrace the effects of losses that raise the entropy of the aspirated flow, or the pumping work associated with it. The overall impact of these (secondary) effects of aspiration can be properly quantified only in the context of a complete engine design, in which the handling of the aspirated flows is explicated. Such an overall evaluation of the effect of aspiration on engine efficiency is outside the scope of this paper.

The structure of this paper is as follows. The aerodynamic design is summarized first, followed by a description of the mechanical design of the stage. The experiment test pack- 
Table 1: Aerodynamic Design Summary

\begin{tabular}{lc}
\hline \hline Tip Speed & $1500 \mathrm{ft} / \mathrm{s}(457 \mathrm{~m} / \mathrm{s})$ \\
Pressure Ratio & 3.4 \\
Mass Flow / Area & $42.5 \mathrm{lbm} / \mathrm{s}-\mathrm{ft}^{2}$ \\
Rotor Face Axial Mach No. & 0.65 \\
Stage Exit Mach No. & 0.5 \\
Rotor Peak Mach No. (rel.) & 1.5 \\
Stator Peak Mach No. (abs.) & 1.5 \\
Peak Diffusion Factor (rot./sta.) & $0.76 / 0.68$ \\
Rotor Work Coefficient $\left(\Delta \mathrm{H} / \mathrm{U}^{2}\right)$ & 0.7 \\
\hline \hline
\end{tabular}

Table 2: Stage Geometry Characteristics

\begin{tabular}{lc}
\hline \hline Rotor Inlet $\left(\mathrm{r}_{\text {hub }} / \mathrm{r}_{\text {tip }}\right)$ & 0.40 \\
Stator Exit $\left(\mathrm{r}_{\text {hub }} / \mathrm{r}_{\text {tip }}\right)$ & 0.81 \\
Blade Count (rot/stat) & $26 / 31$ \\
Average Solidity (rot/sta) & $2.5 / 2.5$ \\
Aspect Ratio (rot/sta) & $1.2 / 0.8$ \\
\hline \hline
\end{tabular}

age, instrumentation, and data reduction procedure are briefly described. The experimental results are discussed next and compared with the multi-stage CFD analyses. Lastly, the important conclusions and implications of the results of the test program are enumerated.

\section{AERODYNAMIC DESIGN}

The computational system assembled to design the aspirated fan stage consists of the quasi-3D MISES integral boundary layer solver [4] coupled with an axisymmetric solver described by Merchant [5]. The blade shapes incorporate several unique design features, which enable the high loading. The details of the aerodynamic design and design procedure can be found in Merchant [5].

Three-dimensional viscous analysis of the stage, using the multi-stage average passage APNASA code developed by Adamczyk [6], was a critical component in the design process. The high supersonic Mach numbers in the blade rows, close blade row spacing, coupled with the very high blade loading demanded more accurate blade row matching than is possible with mixing-plane approaches. While the blade design was carried out using the quasi-3D design system, modifications to blade geometry, primarily incidence changes, were made using information extracted from the 3D APNASA solution.

In addition to the design point analysis, an off-design study along the operating lines was also performed using APNASA in order to assess the performance of the stage at lower tip speeds, and to develop a test plan for the experiment. Two such operating lines were calculated, one close to stall (high op line) and one sufficiently away from stall (low op line). The computational mesh used for all the analyses consists of 389 axial points from

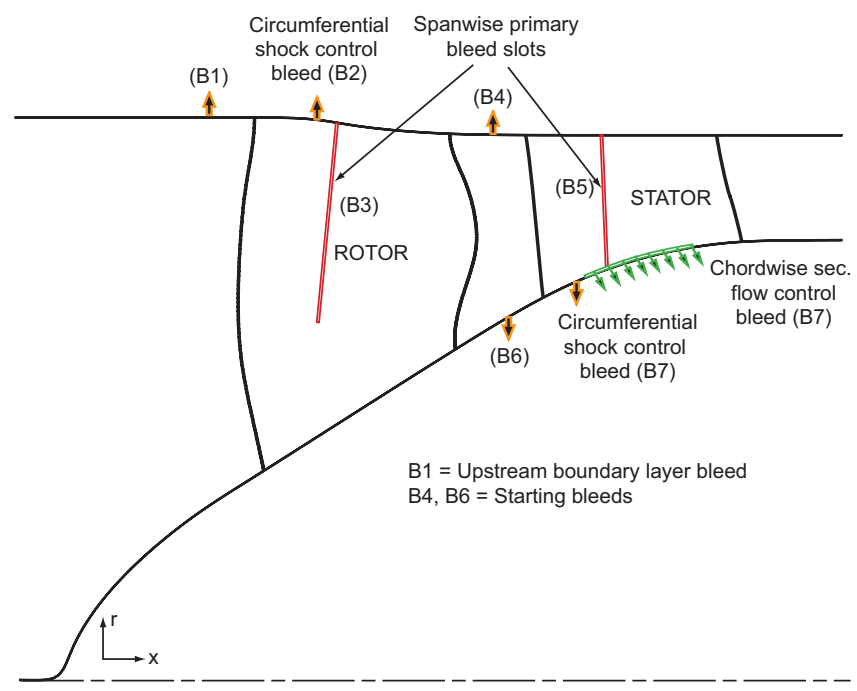

Figure 1: Stage aspiration scheme.

rotor inlet to stator exit, 51 circumferential, and 51 spanwise grid points. The APNASA code was modified with a transpiration boundary condition on the blade and flowpath surfaces to model the effect of aspiration.

The aerodynamic design characteristics of the stage are summarized in Table 1, and the geometric characteristics are summarized in Table 2. The diffusion factors were calculated using the definition of Lieblein et al. [7]. The choice of tip speed, specific flow, and inlet/exit Mach numbers are consistent with modern supersonic high throughflow fans $[8,9]$. The aspect ratio and average solidities of the stage are also similar to such modern fans. The peak Mach numbers, noted in Table 1, occur at the rotor tip and the stator hub. The rotor was designed to achieve a free vortex work profile, and the stator was designed to turn the flow to axial conditions at the stage exit.

The aspiration scheme is illustrated in Figure 1, and the design aspiration fractions are given in Table 3. The designations refer to the experiment setup and will be discussed in the section describing the test package. The aspiration scheme consists of primary aspiration slots on the rotor and stator suction surfaces, and secondary aspiration on the hub and shroud surfaces. The location and flow fraction of the primary aspiration was optimized in the quasi-3D design process. The secondary aspiration

Table 3: Design Aspiration Requirement

\begin{tabular}{lcc}
\hline \hline $\begin{array}{c}\text { Aspiration } \\
\text { Location }\end{array}$ & Designation & $\begin{array}{c}\text { Aspiration } \\
\text { Fraction, \% }\end{array}$ \\
\hline \hline Rotor Shroud & B2 & 1.0 \\
Rotor Spanwise & B3 & 1.5 \\
Stator Spanwise & B5 & 2.0 \\
Stator Hub (circumferential) & B7 & 1.0 \\
Stator Hub (chordwise) & B7 & 1.0 \\
\hline \hline
\end{tabular}


consists of slots on the rotor shroud and stator hub surfaces to prevent shock-induced separation and growth of secondary flow. The location and flow fractions were determined by examining the $3 \mathrm{D}$ solution, but no attempt was made to optimize their location and flow fractions. Bleeds B1, B4, and B6 were present only in the experiment, and were not included in the CFD analysis. Note that the stator hub circumferential and chordwise bleed have the same designation (B7) since they are discharged into the same cavity in the experiment.

\section{MECHANICAL DESIGN}

As the main purpose of the experiment was to assess the viability of aspiration from the aerodynamic standpoint, the mechanical design became a matter of devising a configuration that would meet the mechanical requirements, while providing the shape and tip speed capability dictated by the aerodynamic design. This is a different logical structure than is usual for compressor stages, where the structural considerations generally play a larger role in the overall design optimization. The desire for as clean an aerodynamic design as possible led to the use of a tip shroud in order to eliminate the tip clearance flow. In addition, the tip shroud was attractive as a means for transporting the aspirated flow from the blades to the rotor housing.

The features dictated by the aerodynamic design posed an unusual set of constraints for the mechanical design of the rotor in particular. Finite element calculations showed that the blade stresses due to the high tip speed and large camber and twist of the blades were so high as to be unacceptable, except for the highest strength-to-weight ratio titanium alloys such as Ti-6246, which was selected for the rotor. Welding was ruled out by the choice of this alloy. Stress calculations also indicated that the shroud, at the design tip speed of 1,500 $\mathrm{ft} / \mathrm{sec}$, was beyond its self-supporting limit, and given the already high stresses in the blades, it was not feasible to carry much of the centrifugal load of the shroud on the blades. This led to the decision to use a graphite-polymer composite winding on the shroud to make it essentially self-supporting. The amount of composite was chosen so that the average radial growth of the shroud would match that of the blade tips (without the shroud). This would result in only local radial load transfer from the blades to the shroud. The shroud does however greatly increase the torsional stiffness of the blades in the tip region, essentially eliminating flutter issues, and potential structural problems due to the bleed passages in the blades.

Machining the high solidity rotor and stator blades, bleed passages, and bleed slots as bladed disks posed another set of challenges. These were met by dividing the blade rows into forward and aft disks on a plane perpendicular to the axis of rotation. Halving the blade chord enabled machining of the high solidity blades from single disks, and the suction passages were then machined into the two halves from the separation plane. The assembly of the blade rows involved bolting the forward and aft disks together at the shroud and at the hub. This concept is illustrated for the rotor in Figure 2.

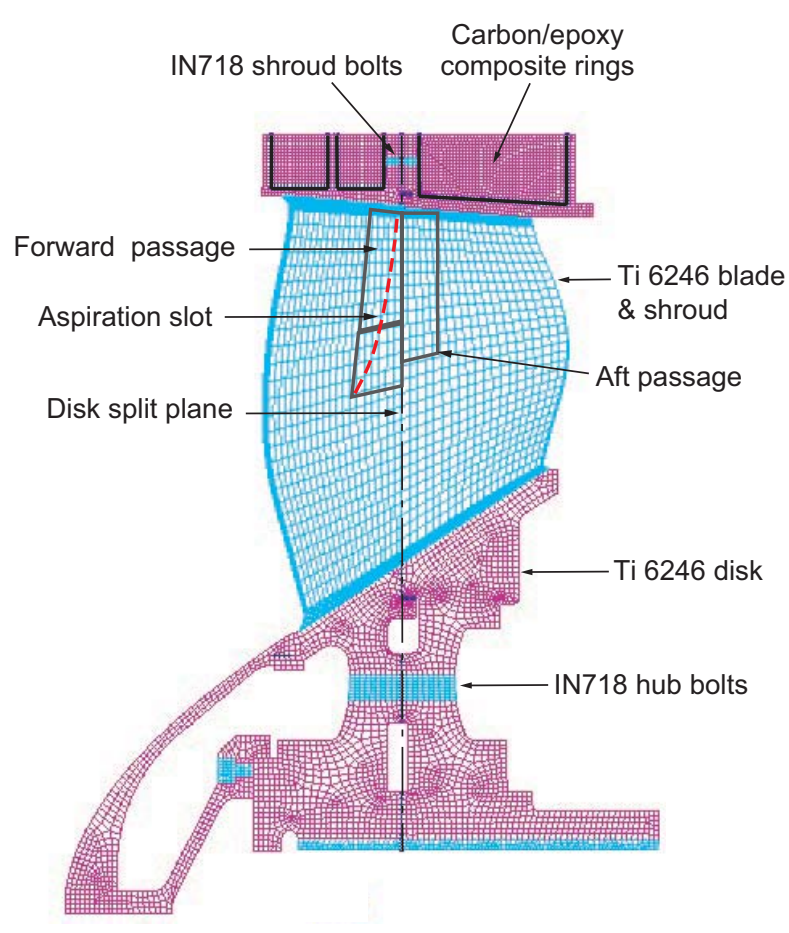

Figure 2: Rotor structural concept.

The composite winding of the shroud was implemented as three separate rings in channels in the titanium shroud as shown in Figure 2. The front disk carried two rings separated by a land for the rotor shroud bleed, and the aft disk carried a single composite ring. The primary aspirated flow was taken from the suction surface of the blade through slots into the radial passages and discharged from the tip at an angle of 45 degrees, against the direction of rotation. This was done to minimize the pumping work for the bleed flow, and consequently the temperature of the aspirated flow circulating in the rotor casing.

The stator suction surface aspirated flow was carried through the radial passage into the casing manifold shown in Figure 3.

\section{TEST PACKAGE}

The aspirated compressor test package consisted of the rotor, stator, and a specially designed casing. The casing sealed the rotor bleed flows from the core flow and collected the high swirl flow from the rotor shroud. The test package installed in the rig is shown in Figure 3. Seven independently controlled, and metered, boundary layer bleed lines were also key elements of the system. These include, in addition to the 5 design bleeds shown in Figure 1, an inlet boundary layer bleed slot approximately 1 chord upstream of the rotor (B1), an inter-blade casing bleed slot (B4), and an inter-blade hub bleed slot (B6). The stator hub pitchwise and chordwise bleeds were combined into a common bleed line (B7). Bleeds B1, B4 and B6 were not modeled in the aerodynamic analysis or design of the stage. Bleeds B4 and B6 were added to ensure that the stage could be started at part speeds. The bleed exhaust system was designed to keep 


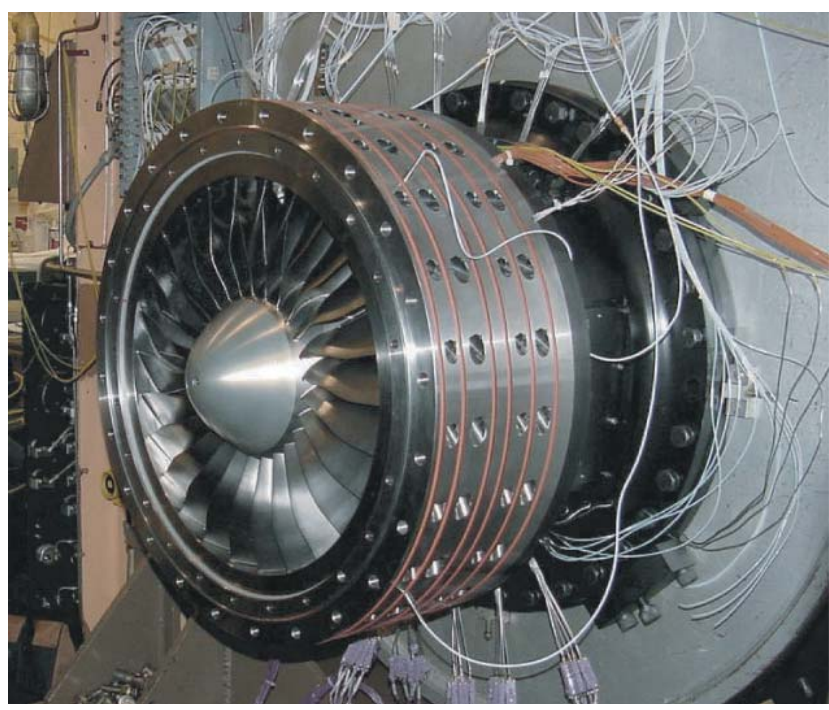

Figure 3: Test package installed in the compressor rig.

the rotor and stator bleed slots operating in a choked condition. A vacuum source was used for all the bleed lines to achieve this condition. Figure 4 shows a close-up view of the rotor, where the spanwise aspiration slot (B3), circumferential shock control bleed (B2), and shroud surface are shown. The NASA Glenn Research Center Multistage Compressor Test Facility, which includes a 15,000 hp drive motor and a 5.21:1 gearbox, was used for this experiment.

\section{INSTRUMENTATION}

The performance of the stage was measured by an array of total pressure and total temperature rakes located 4 inches downstream of the stator trailing edge. Rake designs with a wide acceptance flow angle were chosen to give accurate measurements at a fixed orientation. The temperature rakes were calibrated for temperature recovery versus Mach number. The rakes provided seven spanwise measurements at six equally spaced pitchwise locations covering one blade pitch, resulting in a total of 42 measurements at the stage exit. Wall static taps were the only instrumentation located between the rotor exit and stator inlet. There were 10 pitchwise static taps, on the hub and casing surfaces, covering 1.5 blade pitches, and located 0.125 inches upstream from the stator leading edge. Stator leading edge instrumentation was not implemented in this experiment, so the rotor spanwise performance could not be measured. Bleed flow rates (B1-B7) were measured using an independently metered and controlled bleed system. Dynamic pressure measurements were obtained from the flow path casing about one chord upstream of the rotor and were used to detect stall. Pressure and temperature near the rotor shroud labyrinth teeth rub areas were measured to monitor the shroud condition, and an infrared thermocouple was installed to directly monitor the temperature of the shroud composite material. Rotor shroud radial growth and axial posi-

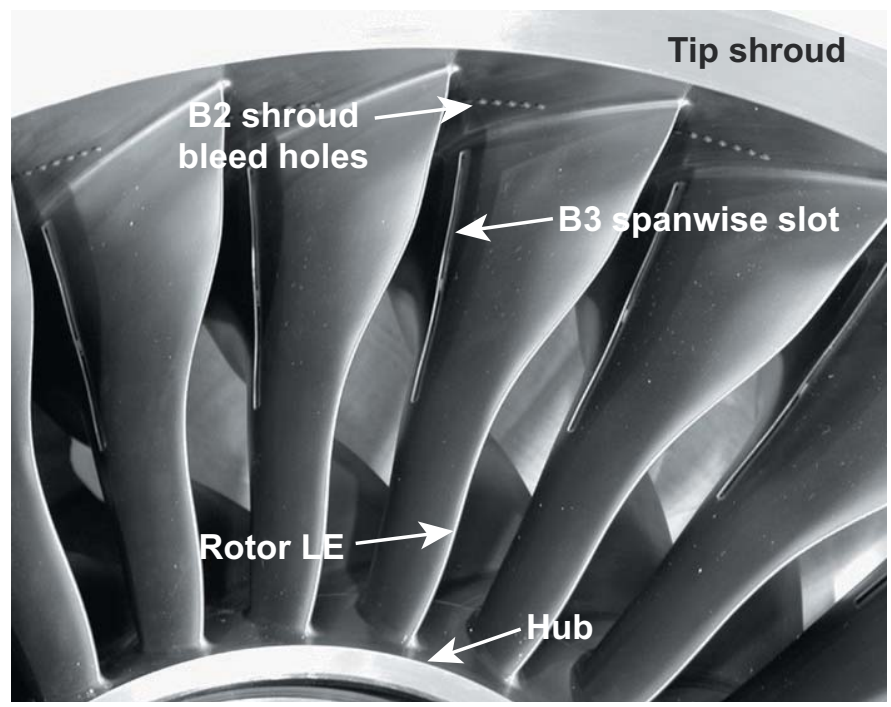

Figure 4: Rotor aspiration scheme.

tions were closely measured. Inlet airflow was determined from an upstream ASME orifice. The health of the facility during the test was constantly monitored via the measured pressures, temperatures, flow rate, and vibration levels.

\section{DATA REDUCTION PROCEDURE}

Orifice weight flow, total pressures, rotor RPM, and temperature were all corrected to standard day conditions based on inlet plenum conditions. The Mach number at each rake port was determined by a linear interpolation of the inner and outer flowpath walls static pressures and the total pressure obtained from that rake port. The pressures and temperatures were area averaged to obtain the overall performance and throughflow efficiency. At the higher operating speeds from $90 \%$ to $100 \%$, total temperature rakes elements were damaged during the experiment and were not replaceable. Measurements from sister rake elements located at the same radial position one pitch apart were substituted in place of the lost measurements and used in the area averaging procedure. In some cases, where these redundant measurements were also not available, the total temperature was substituted by judiciously interpolating between measured data points. The overall area-averaged total temperature and efficiency were calculated with and without this substitution, and the effect on the overall result was found to be negligible.

\section{RESULTS AND DISCUSSION}

The aspirated fan stage was tested from $50 \%$ to $100 \%$ design speed. Speedlines from choke to stall were obtained at $50 \%$ to $85 \%$ speed, and from choke only to the predicted low op line at $90 \%, 95 \%$, and $100 \%$ speed due to concerns about the structural integrity of the rotor. The experimental results presented and discussed in this section include: 1) the overall stage performance, 2) sensitivity of the stage performance to design aspiration flows, 


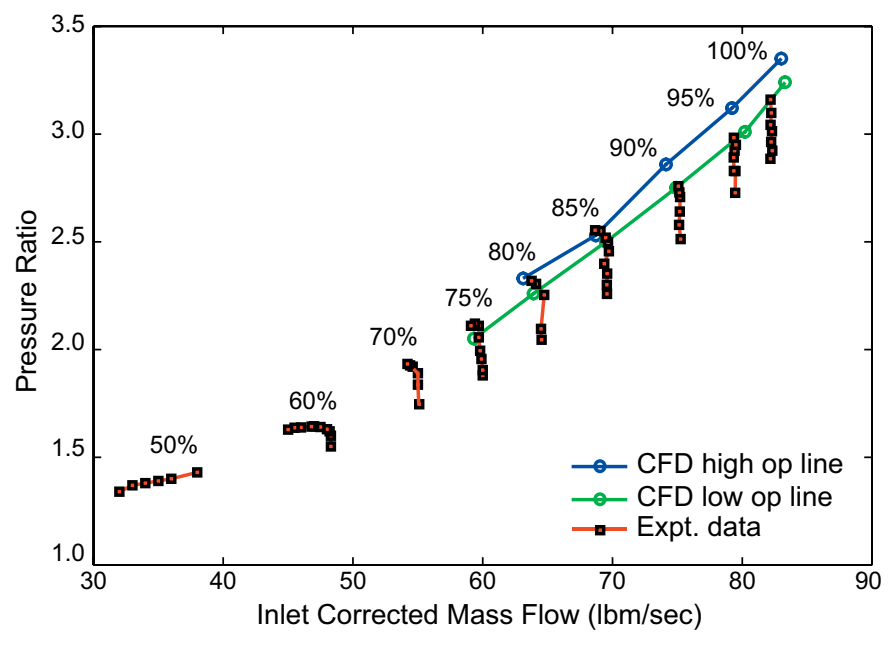

Figure 5: Compressor pressure ratio performance map.

stage upstream bleeds, and starting bleeds, and 3) measurements at the stage exit and between the rotor and stator. The experimental results are compared to CFD calculations carried out using APNASA on the two operating lines, which represent fixed exit corrected mass flow boundary conditions in the code. The bleed flows are presented as fractions of the inlet corrected flow.

\section{1) Overall Stage Performance}

The measured pressure ratio and efficiency of the stage are shown in Figures 5 and 6 . The overall measured pressure ratios and mass flows are seen to be in good agreement to the predicted performance of the stage.

On the $50 \%, 60 \%$, and $70 \%$ speedlines, the inlet boundary layer bleed B1 was set to $1 \%$ of stage core flow at that speed, no interstage bleed was used, and all other bleeds were flowing at their individual maximum capacities (wide open). The stalling flow rate was difficult to determine on $50 \%$ and $60 \%$ speedlines as indicated by the measurements. At $70 \%$ speed, the stage exhibited a well-defined and repeatable stall point, and the total mass flow range for this speed was $1 \mathrm{lbm} / \mathrm{sec}$. A peak pressure ratio of 1.93 , at a corrected mass flow of $54.2 \mathrm{lbm} / \mathrm{sec}$, and adiabatic efficiency of $89 \%$, were recorded.

At $75 \%$ speed, the stage could not be operated without the casing starting bleed B4, and stalled when the bleed was closed. Bleed B4 was therefore set to $1 \%$ of the stage inlet flow, and hub starting bleed B6 was turned off, to obtain the speedline data. The measured pressure ratio closely matches the APNASA calculation, but the measured mass flow rate is $0.8 \%$ higher than the calculated value. This can be attributed to the effect of bleeds B1 and B4 that were not included in the APNASA calculation. A peak pressure ratio of 2.12 , at $59.4 \mathrm{lbm} / \mathrm{sec}$, and an adiabatic efficiency of $88.6 \%$ were recorded. The stage behaved similarly at $80 \%$ speed, and speedlines were measured with the inlet boundary bleed $\mathrm{B} 1$ set to $1 \%$. A peak pressure ratio of 2.32 at 63.7 $\mathrm{lbm} / \mathrm{sec}$, and an adiabatic efficiency of $88.5 \%$ were recorded.

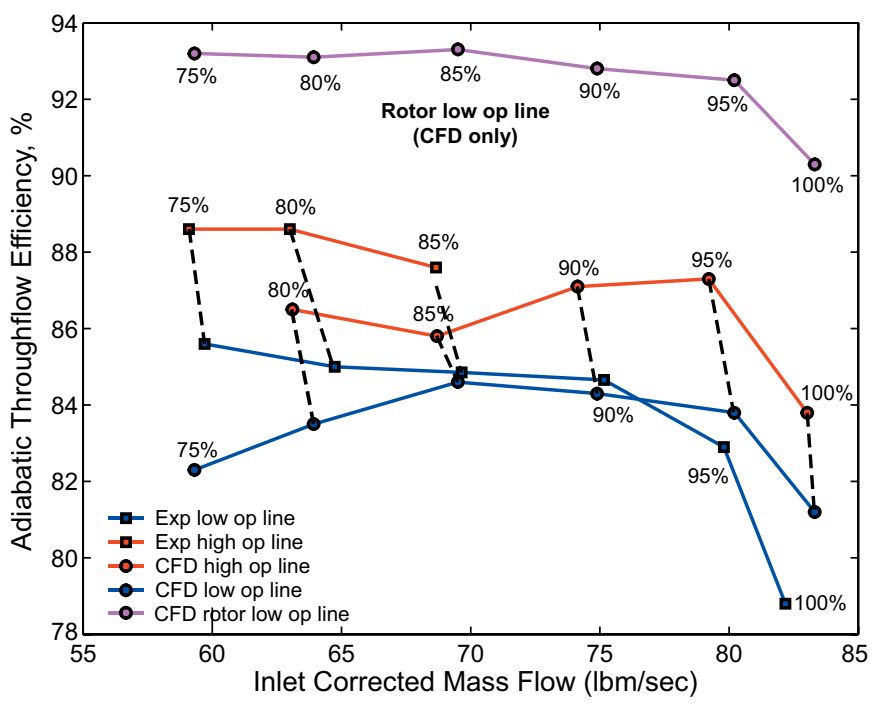

Figure 6: Measured and calculated efficiences on the low and high op lines.

The measured pressure ratios closely match the calculated low and high op line points; however, the measured mass flow rate is $1.2 \%$ higher than the calculation due to the presence of additional bleeds B1 and B4. At 85\% speed, the starting bleeds B4 and B6 were required initially to achieve stable operation and were subsequently turned off. The inlet bleed B1 was set at $1 \%$ to obtain the speedline. Once again the speedline closely matches the CFD prediction. The stalling pressure ratio is $1 \%$ higher than the predicted point on the high op line. The difference between the measured and predicted mass flow is negligible despite the presence of $1 \%$ bleed B1 in the test. A peak pressure ratio of 2.55 at $69 \mathrm{lbm} / \mathrm{sec}$, and an adiabatic efficiency of $87.6 \%$, were recorded at this speed.

At $90 \%, 95 \%$ and $100 \%$ speed, starting bleeds were not required to maintain steady-state operation of the stage, and the upstream bleed was also not used at these speeds. At $90 \%$ speed excellent agreement is seen between the measured pressure ratio and mass flow and the CFD calculation at the low op line point. A pressure ratio of 2.76 , at $75.2 \mathrm{lbm} / \mathrm{sec}$, and an adiabatic efficiency of $84.7 \%$ were recorded. At $95 \%$ and $100 \%$ speed, the pressure ratios lie on the predicted low op line, but the measured mass flows are $0.91 \mathrm{lbm} / \mathrm{sec}(1.1 \%)$ and $1.2 \mathrm{lbm} / \mathrm{sec}(1.5 \%)$ lower than the predicted mass flow rates, respectively. At 95\% speed, a pressure ratio of 2.99 at $79.3 \mathrm{lbm} / \mathrm{sec}$, and an adiabatic efficiency of $82.8 \%$ were recorded. At $100 \%$ speed, a pressure ratio of 3.17 at $82.1 \mathrm{lbm} / \mathrm{sec}$, and an adiabatic efficiency of $78.7 \%$ were recorded. The lower than predicted mass flows and pressure ratios at these speeds can be attributed primarily to the lower measured aspiration flow fractions than the design intent.

The measured efficiencies, shown in Figure 6, are at least 2 points higher than the predicted efficiencies along the high op line. Similarly, higher efficiencies were also measured along the low op line up to $90 \%$ speed. The higher measured efficiencies 
may be attributed in part to the presence of the upstream bleed B1 and starting bleeds B4 and B6 at the lower operating speeds. However at $90 \%$ speed, even without these additional bleeds, the measured efficiency is $0.5 \%$ higher than the predicted value.

A gradual decrease is observed in the measured stage efficiency with increasing operating speed. At $95 \%$ and $100 \%$ speed a rapid decrease in efficiency occurs in the measured and predicted efficiencies. The larger drop in the measured efficiency compared to the CFD predictions can be attributed to the significantly lower measured aspiration flow fractions (see Figure 8) than the design intent. This rapid decrease in the efficiency at $95 \%$ and $100 \%$ speed can be related to the significant changes in the flow behavior seen in the CFD calculation performed with design intent aspiration flow rates (Figure 7). At $100 \%$ speed the rotor tip flow shows a large region of low momentum fluid, and a similar region of low momentum flow is also present in the stator hub
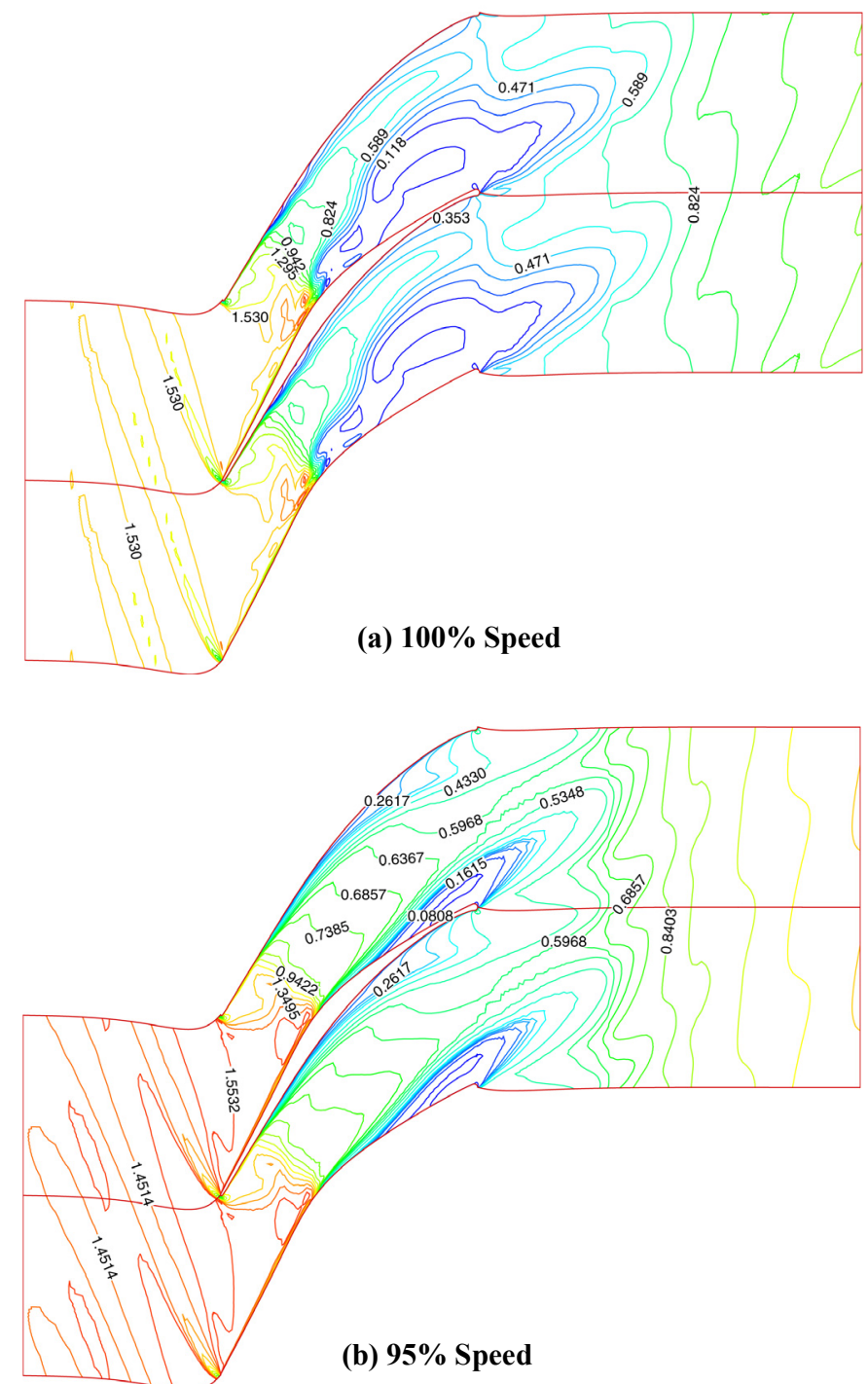

Figure 7: Rotor tip flow field (relative Mach number).

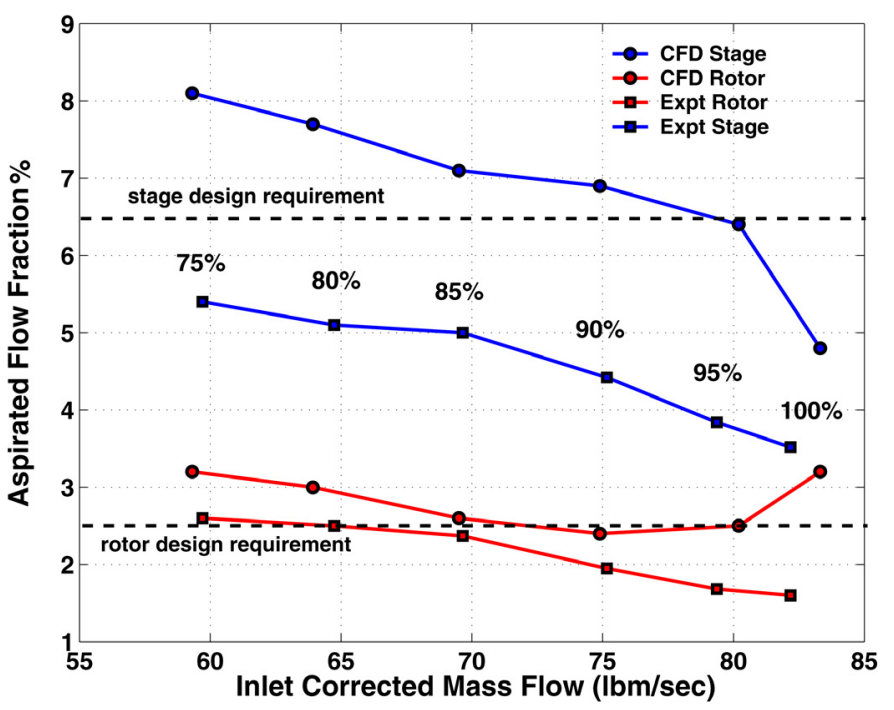

Figure 8: Measured and calculated aspirated flow.

region. Unstarting of the shock system in the presence of this low momentum flow is prevented solely due to the presence of aspiration downstream of the shock. At $95 \%$ speed, a significant reduction of this low momentum flow region and increase in diffusion in the rotor passage is seen, and there is also a reduction in the inlet relative Mach number. The aspiration is clearly seen to control the flow separation downstream of the shock. A similar improvement in the flowfield also occurs in the stator hub region. The result is an overall improvement in stage performance observed between $100 \%, 95 \%$, and $90 \%$ of the design speed.

Figure 6 also shows the calculated rotor efficiency along the low op line. The rotor efficiency is seen to be above $92 \%$ along the entire low op line decreasing to $90 \%$ at design speed $(100 \%)$. This can be attributed primarily to the changes in the flow behavior seen in Figure 7.

\section{2) Bleed Sensitivity}

The sensitivity of the stage performance to bleed flow rates is discussed first in the context of the design aspiration requirement given in Table 3 followed by the effect of the additional starting and upstream bleeds. Figure 8 shows the measured and calculated aspiration flow rates, as fractions of the stage inlet corrected flow, along the low and high op lines. The variation in aspiration flow along a speedline at a fixed operating speed was found to be negligible. The rotor aspiration includes bleeds $\mathrm{B} 2$ and $\mathrm{B} 3$, and the stage aspiration includes, in addition to the rotor, bleeds B5 and B7 consistent with the CFD calculation. The upstream and starting bleed flow fractions are not included. The measured aspirated flow fraction is almost $30 \%$ lower than the flow fraction imposed in the CFD calculation. The dashed line indicates the design intent aspiration fractions of $2.5 \%$ for the rotor and $6.5 \%$ for the stage. At $100 \%$ speed, the measured rotor aspiration was $1.6 \%$ and total stage aspiration was only $3.5 \%$, 
which is at almost half the design aspiration requirement. The sensitivity of the stage performance to aspiration was studied at $90 \%$ speed using CFD, where the rotor aspiration was decreased to $1.1 \%$ and the stage aspiration to $3 \%$. This resulted in a $2 \%$ decrease in the rotor and stage pressure ratios, a $6 \%$ decrease in the stage mass flow, and a 1 point decrease in stage efficiency. The measured performance, in comparison, at $90 \%$ speed is almost identical to the CFD prediction at an aspiration fraction $30 \%$ below the design intent. At $95 \%$ speed, the measured efficiency is 1 point lower, and mass flow $1.1 \%$ lower, than the CFD prediction at aspiration fraction $40 \%$ below the design intent. The experimental data therefore indicates robust performance, and a lower sensitivity to decrease in the aspiration flow than observed in the CFD study.

The starting bleeds were required to operate the stage at $70 \%, 75 \%$, and $80 \%$ speed. At $85 \%$ speed the casing bleed B4 was required to initially stabilize the stage, but was not required continuously. At $75 \%, 80 \%$, and $85 \%$ of design speed, both the starting bleeds were required in addition to opening the throttle valve to recover from stall. The stage, in general, was found to be more sensitive to the casing starting bleed B4 at these speeds.

At $80 \%$ speed, several points were also taken with the inlet boundary layer bleed turned on. At similar pressure ratios the efficiency of the stage with inlet boundary layer bleed on was about 1.2 points higher, and the stage mass flow rate increased by $1.3 \mathrm{lbm} / \mathrm{sec}(2 \%)$. At $85 \%$ speed, several points were also taken with the inlet boundary layer bleed off $(\mathrm{B} 1=0)$. At similar pressure ratios, the efficiency of the stage with inlet boundary layer bleed off was about 0.6 points lower, and the stage mass flow rate was decreased by about $1 \mathrm{lbm} / \mathrm{sec}(1.4 \%)$.

\section{3) Stage Exit Profiles}

Figure 9 shows the measured and predicted stage exit total pressure profiles on the low operating line. The profiles were

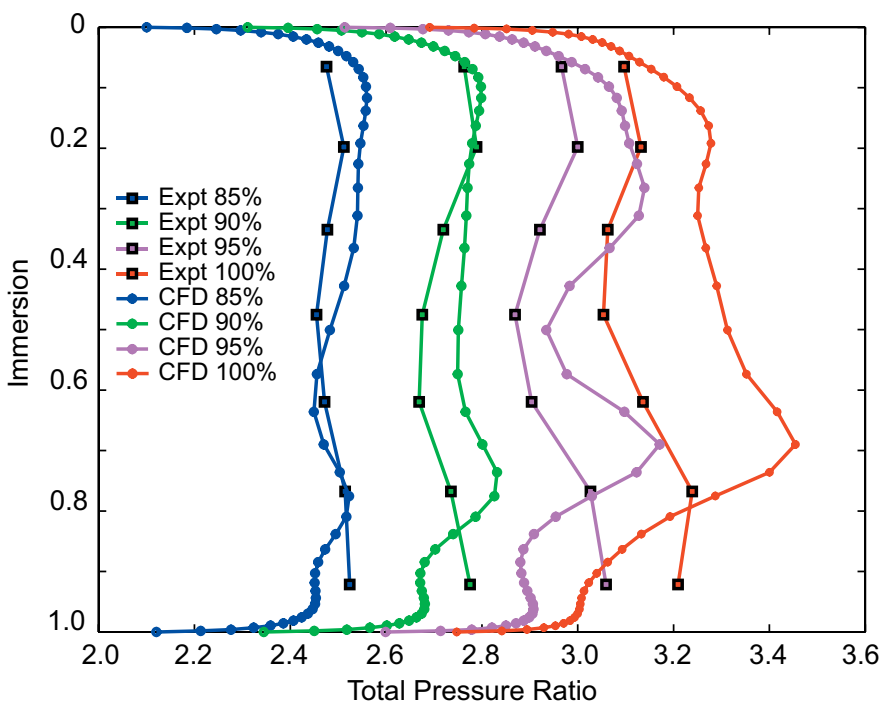

Figure 9: Stage exit measured and calculated total pressure profiles on low op line.

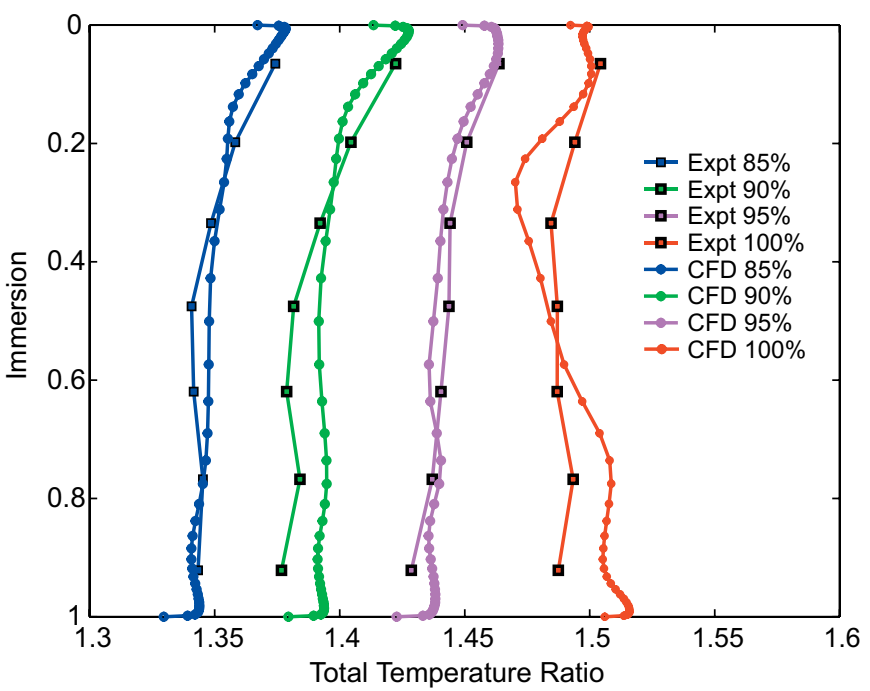

Figure 10: Stage exit measured and calculated total temperature profiles on low op line.

obtained by area averaging the experimental total pressure measurements in the pitchwise direction. The experimental profiles are seen to be more uniform than the profiles predicted by CFD. Good agreement is seen between the measured and calculated profiles at $85 \%$ and $90 \%$ speed. At $95 \%$ and $100 \%$, while the overall pressure ratio is lower, the spanwise variation is in good agreement with the CFD prediction. The experimental data shows a consistently lower pressure ratio defect in the hub region than the CFD. The CFD captures the decrease in pressure ratio at mid-span at all the speeds, but predicts a larger total pressure defect than the experimental profiles.

Figure 10 shows the corresponding measured and predicted total temperature profiles. The measured and calculated profiles are seen to be in good agreement. The CFD calculation captures the total temperature increase near the casing, which can be attributed to the additional temperature rise due to the rotating shroud. At $90 \%$ and $100 \%$ speed, the measured total temperature profile is seen to be lower than the predicted profile below midspan.

\section{4) Stator Static Pressure Measurements}

Figure 11a shows the pitchwise variation of static-to-inlet total pressure ratio at the stator leading edge at $85 \%$ speed. The peak static pressure is about $10 \%$ higher in the experiment than in the CFD calculation. The minimum pressure on the pressure side is well predicted, but the pressure rise at mid-passage, due to crossing of the leading edge bow shock, is higher in the CFD calculation. The lower mid-passage pressure may indicate a higher Mach number and a bow shock that is deeper in the blade passage in the experiment compared to the CFD calculation. It should be noted that the starting bleed B6 is located 0.4 inches upstream of the stator leading edge static taps. Although this bleed was nominally turned off, interference from the slot may be contributing to some of the observed differences. The 


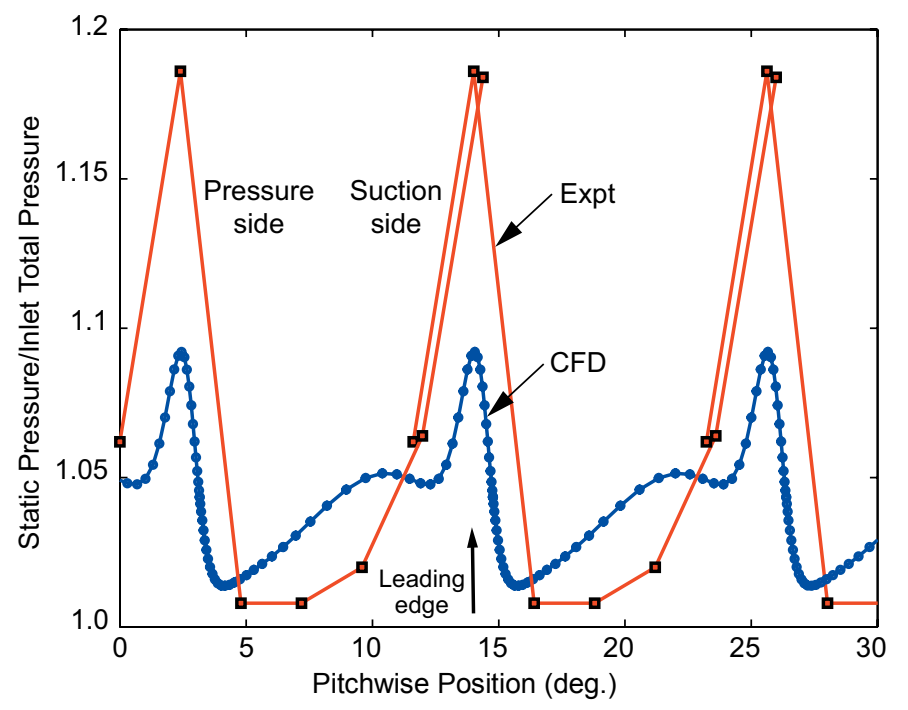

(a) Stator Hub

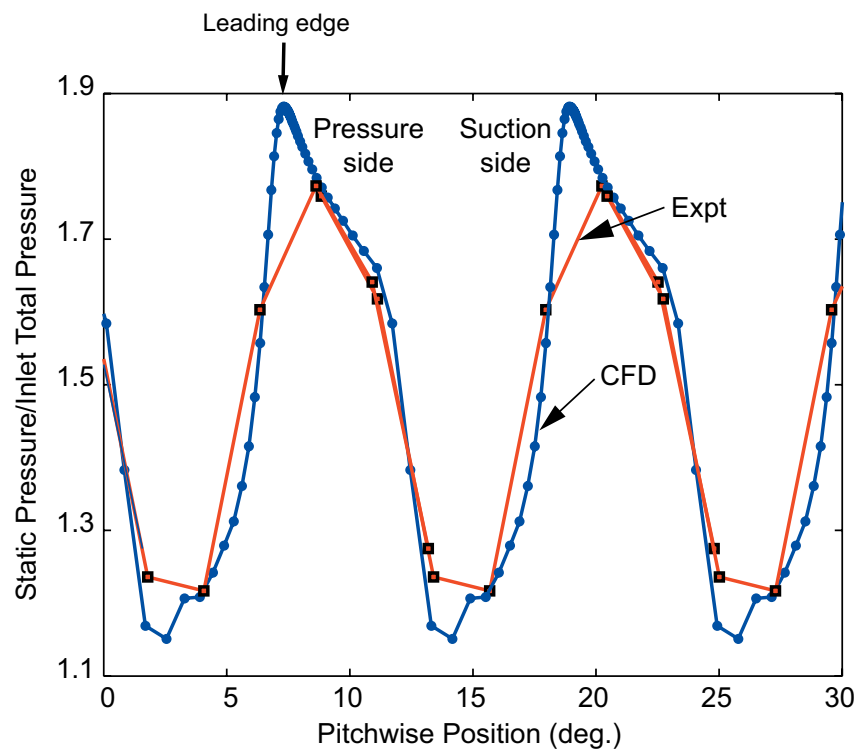

(b) Stator Casing

Figure 11: Pitchwise static pressure variation at the stator leading edge ( $85 \%$ speed).

measured and predicted static pressure variations at the casing at $85 \%$ of the design speed are in excellent agreement (Figure 11b). The CFD solution shows that the pressure rise from $14 \mathrm{deg}$. to 12 deg. on the pressure side is due to crossing of the stator passage shock., and the agreement with measured pressure suggests that the shock positions are therefore in good agreement.

Figures $12 \mathrm{a}$ and $12 \mathrm{~b}$ show the pitchwise variation of staticto-inlet total pressure ratio at the stator leading edge at $100 \%$ speed. Similar to $85 \%$ speed, the measured overall static pressure at the hub (Figure 12a) is observed to be higher than the CFD prediction. The measured and predicted widths of the pressure peaks are in good agreement. The observed pressure peak at

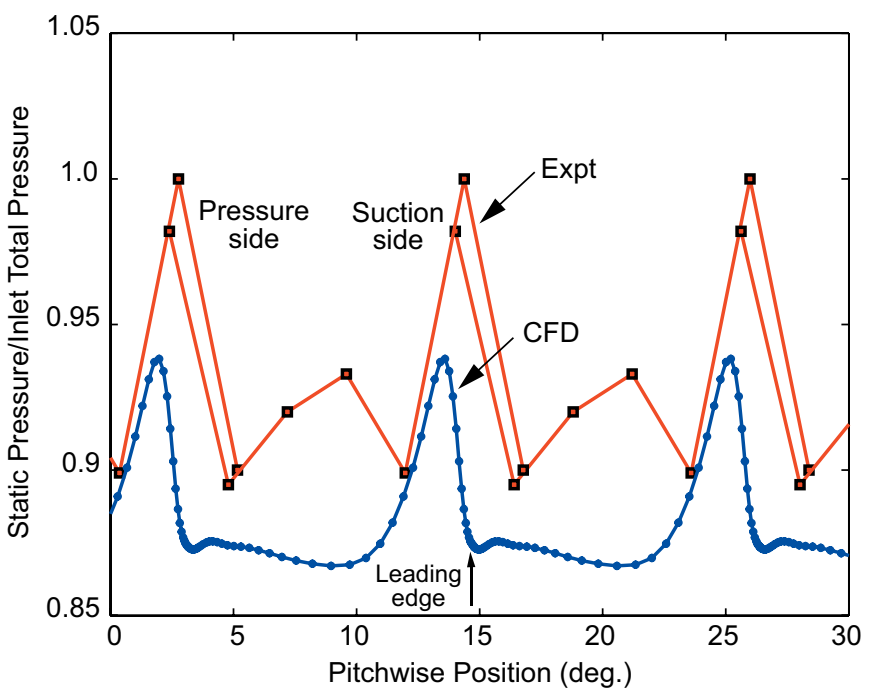

(a) Stator Hub

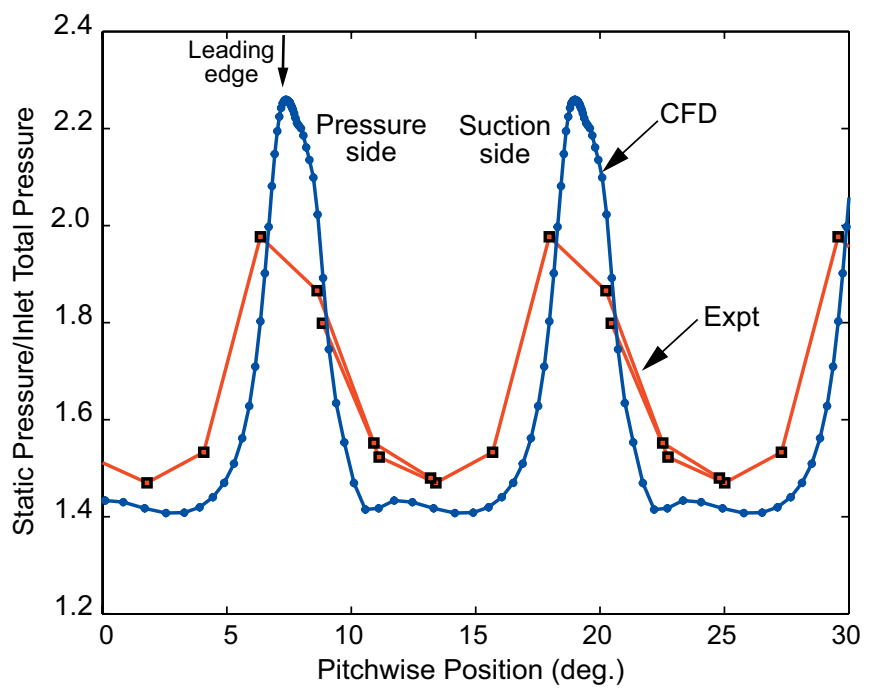

(b) Stator Casing

Figure 12: Pitchwise static pressure variation at the stator leading edge ( $100 \%$ speed).

mid-pitch in the measured pressure indicates that the bow shock may be located further upstream of the stator leading edge in the experiment. As noted above the starting bleed B6 may be contributing to some of the observed differences. The pitchwise static pressure variation at the casing is seen to be in good agreement with $\mathrm{CFD}$, and the minimum pressure and overall variation are well predicted by the CFD calculation. The pressure peak is not adequately captured since none of the static taps are aligned with the stator leading at the casing.

Figures 13a shows the mid-pitch static pressure rise along the stator hub. The approximate locations of the stator leading edge, bleed slot B5, and trailing edge are indicated on the plot. Due to the large pressure tap spacing, the experimental profile does not resolve the initial pressure rise due to the bow shock 


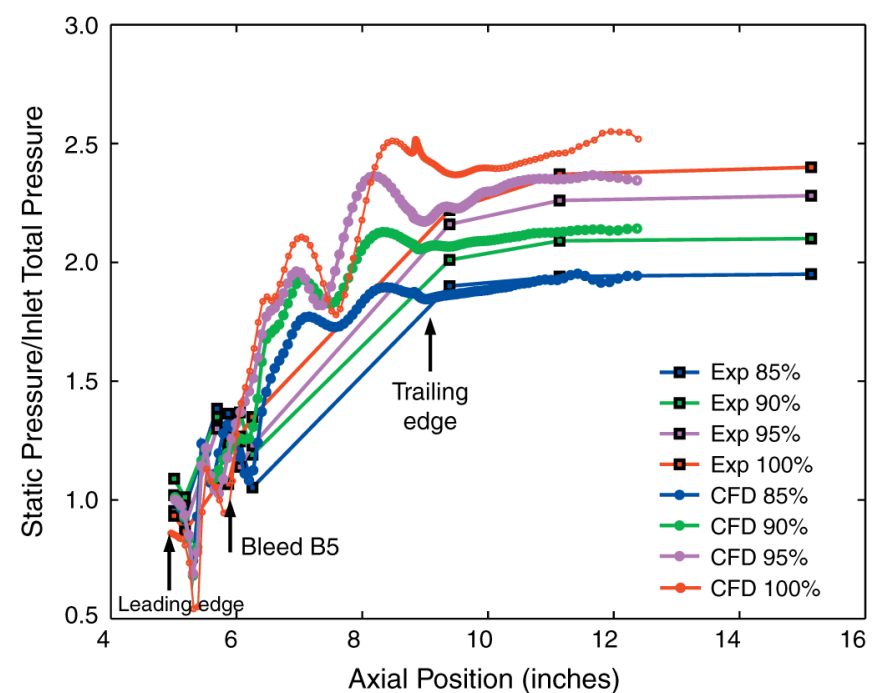

(a) Stator Hub

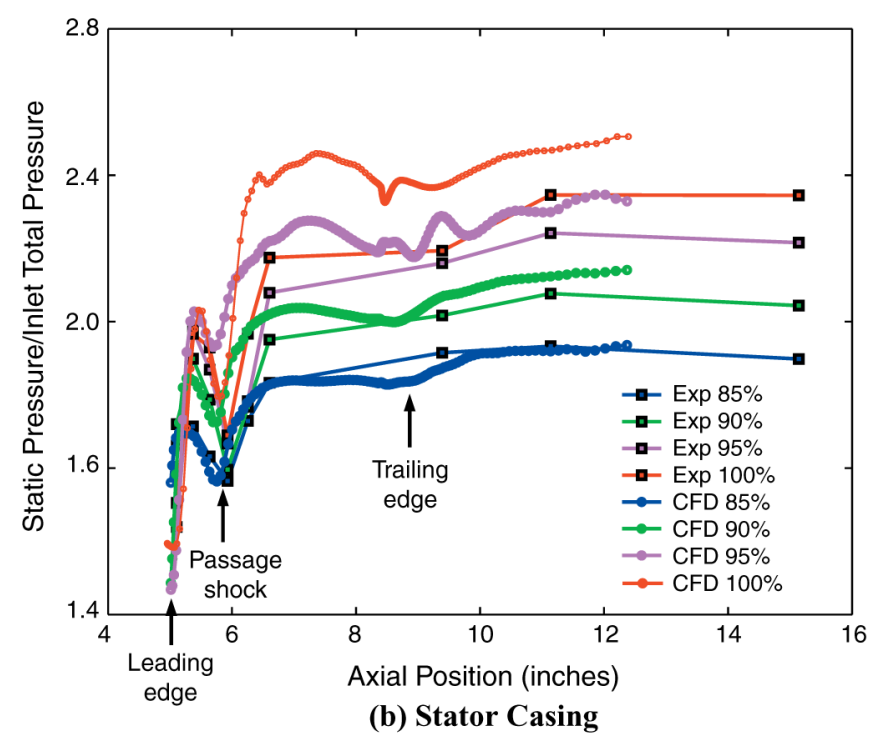

Figure 13: Stator mid-pitch static pressure rise.

seen in the CFD profile, however the measured pressure rise from the leading edge to just downstream of the slot is in good agreement with CFD. The measured exit pressures at $85 \%$ and $90 \%$ speed are also seen to be in excellent agreement with the predicted value. At $95 \%$ and $100 \%$ speed the measured value is lower than the CFD and is consistent with the overall performance discussed above.

Figure 13b shows the mid-pitch static pressure rise along the stator casing. The measured pressure rise in the leading edge region is in good agreement with the CFD prediction. The passage shock position and pressure rise are in excellent agreement at $85 \%$ speed. At $90 \%$ speed the measured passage shock is downstream of the CFD prediction, and moves forward at higher speeds. The measured exit pressure rise at $85 \%$ and $90 \%$ speed are in good agreement with CFD, and lower static pressure rise is measured at $95 \%$ and $100 \%$ speeds, consistent with the overall reduction in pressure ratio and mass flow of the stage at these speeds. At $100 \%$ speed, the stator hub and casing midpitch static pressure rise coefficients are approximately 0.66 .

\section{CONCLUSIONS AND RECOMMENDATIONS}

This program, comprising the design, analysis and test of a very high pressure ratio compressor stage enabled by aspiration, leads us to the following conclusions and recommendations:

1. Removal of the low energy flow in the amount of a percent of the stage inlet mass flow per bleed location does in fact result in an increase in low-loss diffusion, such as to enable designs with approximately double the compressor work at a given tip speed.

2. The CFD flowfield shows that aspiration fixes the passage shock position, particularly in the tip region. The agreement between the measured and predicted performance suggests that, along with enhancing the diffusion of the stage, aspiration is also effective in controlling the shock position and achieving a started shock system at operating speeds above $90 \%$, which is necessary for achieving the desired inlet mass flow and pressure ratio.

3. Although the stage design and aspiration were optimized for the design point, good performance was obtained at offdesign conditions. The measured throughflow efficiency of the stage was consistently higher than the CFD prediction on the low and high operating lines up to $90 \%$ of the design speed.

4. The measured stage performance was found to be less sensitive to reduction in aspiration flow than predicted by the 3D CFD calculation. Performance close to the design intent, and in good agreement with the CFD predictions, was obtained at aspiration flow rates significantly lower than the design intent.

5. The starting bleeds were required for stable operation only from $70 \%$ to $85 \%$ of the design speed. These were also necessary to recover from stall in addition to opening the throttle valve (the stage was not operated to stall above $85 \%$ speed). The rotor exhibited a well-defined entry and recovery from stall once the starting bleeds were opened.

6. The effects of aspiration are quantitatively represented in the computational quasi-3D design system in which the aspiration is modeled by a prescribed mass flux into the wall at the location of a flush slot or hole. The effect of aspiration can therefore be integrated into the blade design process.

7. The quasi-3D design system can be used quite effectively to design blade shapes at high loading levels (with flow conditions extracted from a fully $3 \mathrm{D}$ viscous calculation). The independent design of the blade shapes and design features incorporated in the aspirated stage are an essential ingredient in achieving the high loading while maintaining good throughflow efficiency and minimizing the aspiration requirement. 
8. The 3D viscous analyses using APNASA yielded performance predictions for the compressor stage that were very close to the experimentally observed performance. This has important implications for design of highly loaded stages since an accurate $3 \mathrm{D}$ viscous analysis can augment the quasi-3D design system by providing critical flow information that can be used to refine the design and achieve good blade row matching.

9. The novel mechanical structure devised for the aspirated stage, including a rotor split fore and aft into two integrally bladed halves, with a graphite-polymer wound tip shroud, proved to be mechanically sound and expeditious for the purposes of the experiment.

10. Relaxing the design objectives set forth for this stage, such as the pressure ratio, radial work profile, and stator exit angle, could result in a stage with higher efficiency, lower bleed requirements, a less demanding structure, and lower stator Mach number, the last being a major challenge in this design.

11. In the present design, major effort was focused on optimizing the blade shapes and minimizing the required blade surface aspiration. There are clearly additional opportunities to enhance the performance of future designs, particularly with respect to managing the endwall flows through threedimensional design features, and developing more effective endwall flow control schemes.

\section{REFERENCES}

[1] Kerrebrock, J.L., Drela, M., Merchant, A.A., Schuler, B.J., 1998, "A Family of Designs for Aspirated Compressors," ASME Paper 98-GT-196.

[2] Schuler, B.J., Kerrebrock, J.L., and Merchant, A.A., 2002, "Experimental Investigation of an Aspirated Fan Stage", ASME Paper 2002-GT-30370, ASME IGTI Conference.
[3] Merchant, A.A., Drela, M., Kerrebrock, J.L., Adamczyk, J.J., and Celestina, M., 2000, "Design and Analysis of a High Pressure Ratio Aspirated Compressor Stage," ASME Paper 2000-GT-619, ASME IGTI Conference.

[4] Youngren, H.H., and Drela, M., 1991, "Viscous/Inviscid Method for Preliminary Design of Transonic Cascades," AIAA Paper AIAA-91-2364.

[5] Merchant, A.A., 1999, "Design and Analysis of Axial Aspirated Compressor Stages," PhD Thesis, Massachusetts Institute of Technology, Cambridge, MA.

[6] Adamczyk, J.J., 1985, "Model Equation for Simulating Flows in Multistage Turbomachines," ASME Paper 85-GT-226.

[7] Lieblein, S., Schwenk, F.C., Broderick, F.L., 1953, "Diffusion Factor for Estimating Losses and Limiting Blade Loadings in Axial Flow Compressor Blade Elements," Technical Report RME53D01, NACA.

[8] Wennerstrom, A.J., 1984, "Experimental Study of a HighThroughflow Transonic Axial Compressor Stage," ASME Journal of Engineering for Power, 106, pp. 553-559.

[9] Wadia, A.R., Szucs, P.N., Crall, D.W., 1998, "Inner Workings of Aerodynamic Sweep," Journal of Turbomachinery, 120, pp. 671-682. 


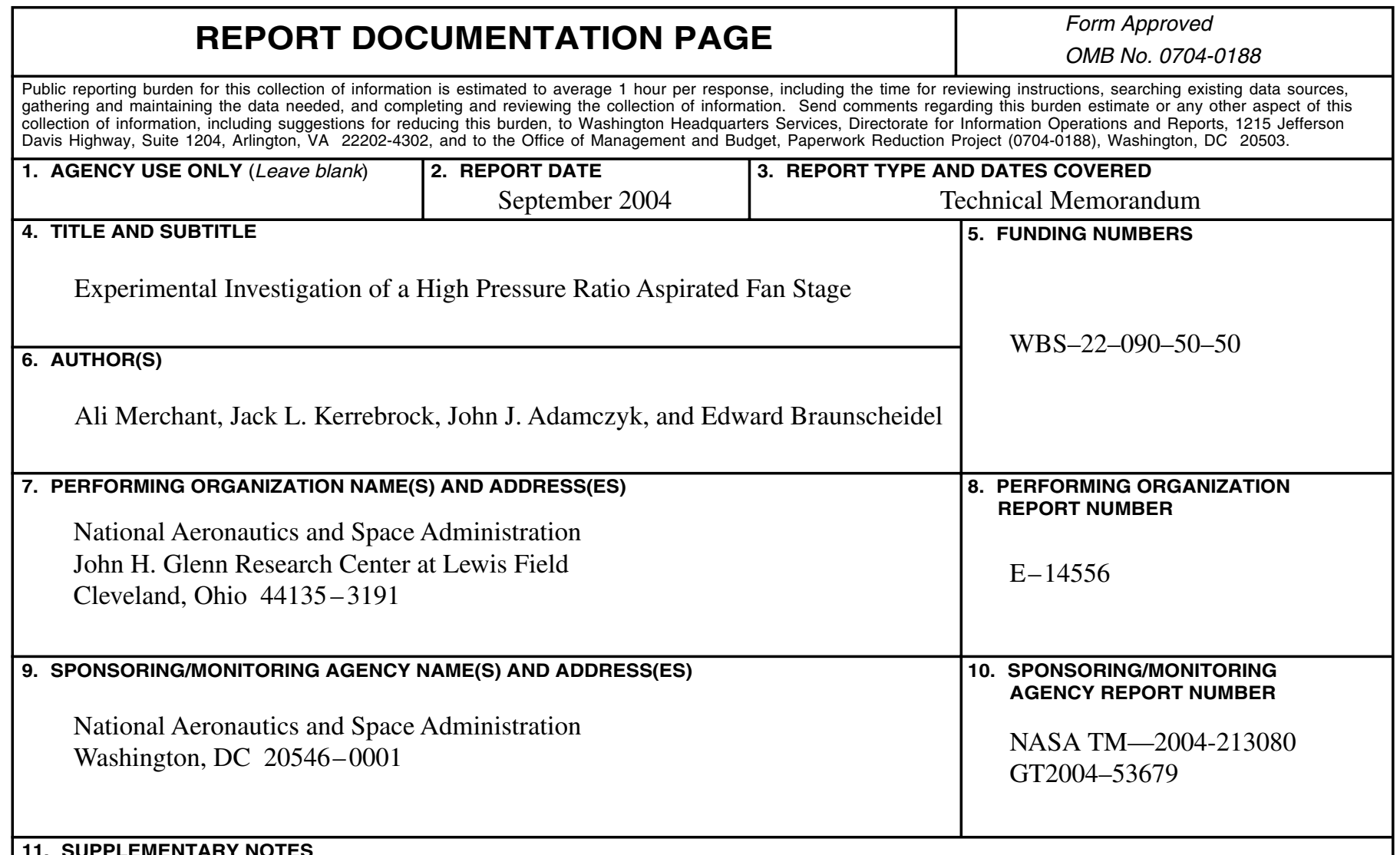

\section{SUPPLEMENTARY NOTES}

Prepared for the Turbo Expo 2004 sponsored by the American Society of Mechanical Engineers, Vienna, Austria, June 14-17, 2004. Ali Merchant and Jack L. Kerrebrock, Gas Turbine Laboratory, Massachusetts Institute of Technology, Cambridge, Massachusetts 02139; and John J. Adamczyk and Edward Braunscheidel, NASA Glenn Research Center. Responsible person, Edward Braunscheidel, organization code 5810, 216-433-6298.

12a. DISTRIBUTION/AVAILABILITY STATEMENT

12b. DISTRIBUTION CODE

Unclassified - Unlimited

Subject Category: 07

Distribution: Nonstandard

Available electronically at http://gltrs.grc.nasa.gov

This publication is available from the NASA Center for AeroSpace Information, 301-621-0390.

13. ABSTRACT (Maximum 200 words)

The experimental investigation of an aspirated fan stage designed to achieve a pressure ratio of $3.4: 1 \mathrm{at} 1500 \mathrm{ft} / \mathrm{sec}$ is presented in this paper. The low-energy viscous flow is aspirated from diffusion-limiting locations on the blades and flowpath surfaces of the stage, enabling a very high pressure ratio to be achieved in a single stage. The fan stage performance was mapped at various operating speeds from choke to stall in a compressor facility at fully simulated engine conditions. The experimentally determined stage performance, in terms of pressure ratio and corresponding inlet mass flow rate, was found to be in good agreement with the three-dimensional viscous computational prediction, and in turn close to the design intent. Stage pressure ratios exceeding 3:1 were achieved at design speed, with an aspiration flow fraction of 3.5 percent of the stage inlet mass flow. The experimental performance of the stage at various operating conditions, including detailed flowfield measurements, are presented and discussed in the context of the computational analyses. The sensitivity of the stage performance and operability to reduced aspiration flow rates at design and offdesign conditions are also discussed.

\section{SUBJECT TERMS} 15. NUMBER OF PAGES

Transpiration; High pressure; Boundary layers; Shrouds; Computational fluid dynamics; Stators; Rotors

17. SECURITY CLASSIFICATION OF REPORT

Unclassified

18. SECURITY CLASSIFICATION
OF THIS PAGE
Unclassified

Unclassified

19. SECURITY CLASSIFICATION
OF ABSTRACT
Unclassified

NSN 7540-01-280-5500
Standard Form 298 (Rev. 2-89)

Prescribed by ANSI Std. Z39-18 298-102 

